\title{
Incidência das Precipitações no município de Ituaçu - BA, no período entre 2000 a 2015
}

\author{
Incidence of Rainfall in the Municipality of Ituaçu-BA, in the Period 2013 to 2015 \\ CONCEIÇÃO ${ }^{1}$, R. S.; OLIVEIRA², D. P. A.; MAIA³, M. R.; LIMA³, E. M. \\ renaildosanttos@hotmail.com
}

\begin{abstract}
Resumo
Este artigo centra-se em analisar a incidência das precipitações no município de Ituaçu, tendo como base os anos de 2000 a 2015. Os dados foram coletados no Instituto Nacional de Meteorologia (INMET). Tal estudo é relevante para o município, visto que os resultados trarão mais clareza sobre a dinâmica climática local e poderá contribuir para possíveis planejamentos ambientais e agrícolas. No estudo das médias mensais da temperatura observou-se que Ituaçu apresenta temperaturas que variam entre 27 e $28^{\circ} \mathrm{C}$ no verão e 22 e $25^{\circ} \mathrm{C}$ no inverno. Comprovou-se que as precipitações no município são altamente variáveis, tanto com relação às médias mensais quanto anuais. Verificou-se que, existem meses em que as precipitações apresentam índices elevados e outros com severa escassez de chuvas. Ou seja, a pluviometria não se mantém em regime padrão mensal ou anual, haja vista que as médias crescem e decrescem de um mês para outro e de um ano para outro. Assim, verifica-se que o município apresenta instabilidade com relação a distribuição das precipitações, ocasionando eventos extremos e alerta à população com relação à vulnerabilidades e riscos, tanto em relação aos longos períodos de seca, quanto aos danos provocados pelo excesso de chuva.
\end{abstract}

Palavras chaves: Índice pluviométrico. Incidência. Temperatura. Semiárido.

\begin{abstract}
Article focuses on analyzing the incidence of precipitation in the municipality of Ituaçu, taking as a basis the years 2000 to 2015. The data were collected at the Instituto Nacional de Meteorologia (INMET). The study is relevant to the municipality, since the results will bring more clarity about the climate dynamic local and may contribute to possible environmental and agricultural plans. In the study of the monthly averages of temperature observed that Ituaçu has temperatures ranging between 27 and $28^{\circ} \mathrm{C}$ in summer and 22 and $25^{\circ} \mathrm{C}$ in winter. It has been proven that the precipitation in the city are highly variable, both with respect to the monthly averages as yearly. It was found that there are months in which the precipitations have high rates and others with severe shortage of rainfall. In other words, the rainfall does not remain in the standard regimen monthly or yearly, considering that the average grow and diminish from one month to another and from one year to another. Thus, it appears that the municipality unstable with respect to distribution of rainfall, causing extreme events and alerts to the population with respect to vulnerabilities and risks, both in relation to long periods of drought, as the damage caused by excessive rain.
\end{abstract}

Key words: Rainfall. Incidence. Temperature. Semiarid

\footnotetext{
${ }^{1}$ Renaildo Santos da Conceição, graduando em Geografia, Universidade Estadual do Sudoeste da Bahia, Vitória da Conquista-BA, Brasl

${ }^{2}$ Débora Paula de Andrade Oliveira, graduada em Geografia, Universidade Estadual do Sudoeste da Bahia, Vitória da ConquistaBA, Brasl
}

${ }^{3}$ Meirilane Rodrigues Maia, Espedido Maia Lima; Professores doutores do Departamento de Geografia/Laboratório de Geografia Física, Universidade Estadual do Sudoeste da Bahia, Vitória da Conquista-BA, Brasil 


\section{INTRODUÇÃO}

O conhecimento sobre os índices pluviométricos e a distribuição das chuvas é de importância significativa para a análise dos espaços urbanos e rurais, uma vez que estes interferem diretamente na dinâmica dos recursos hídricos. A relação entre a precipitação e os dias com chuvas é um indicador relevante para a análise da disponibilidade, escassez de água e a interpretação das condições climáticas. Esses indicadores podem subsidiar pesquisas com enfoques diversos, como a produção agrícola, os estudos do clima e os diagnósticos ambientais.

O regime pluviométrico é um dos elementos meteorológicos que mais exerce influência sobre as condições dos ambientes. Esse elemento apresenta efeito direto sobre o balanço hídrico e configura-se como um dos fatores básicos para o crescimento e desenvolvimento da flora, além de estar intimamente relacionado como a distribuição da fauna e a dinâmica da vida silvestre (SANTOS 2005).

Ao discutir a importância do clima sobre as atividades humanas, Monteiro destaca que "se os processos de organização agrícola afetam negativamente o quadro ecológico, qualquer evento climático fora dos padrões habituais é capaz de deflagrar uma reação em cadeia que não só afeta a produção agrícola como danifica o ambiente” (MONTEIRO, 1981, p. 32).

As variações climáticas influenciam diretamente a produtividade da agricultura de sequeiro no semiárido nordestino. De acordo com Nobre e Molion (1988), a variabilidade das precipitações na região Nordeste do Brasil é produto da associação de diversos elementos que influenciam os sistemas meteorológicos e as mudanças nas configurações de circulação atmosférica de grande escala.

O excesso ou escassez de chuvas é, também, causador de eventos extremos, como longos períodos de estiagem, enchentes, inundações e deslizamentos de terra entre outros. Enfatiza-se, ainda, que os prejuízos podem ser mais amplos em escalas locais. Para Conti e Furlan,

Denominam-se excepcionalidades climáticas os fenômenos atmosféricos que se desviam muito do habitual e, apesar de concorrer com certa raridade, trazem graves conseqüências para a vida humana e para os outros elementos da natureza. Há vários outros desvios do comportamento atmosférico que perturbam as atividades humanas. Os efeitos de uma estiagem severa em área agrícola, por exemplo, podem fazer diminuir a oferta de alimentos, determinando elevação do custo de vida (CONTI; FURLAN, 2011, p. 83-84).

Segundo Conceição et al (2015), o sistema atmosférico se relaciona com o habitat dos seres vivos e estes, muitas vezes, ainda sofrem com as suas dinâmicas e alterações, como as variações das tempestades, enchentes, geleiras, terremotos e sensação térmica. Desse modo, considera-se que a 
dinâmica atmosférica articulada a outros fatores naturais e socioeconômicos, constitui-se como um fator importante na Análise ambiental.

Em concordância com Bazzano, Eltz e Cassol (2007), acredita-se que, com a análise da distribuição das precipitações, assim como de práticas agrícolas que resguardem e mantenham sua cobertura, é possível elaborar um melhor planejamento de estruturas de conservação do solo.

Nessa perspectiva, Sudo (2000) complementa que para o estudo das condições de umidade e sequidão climática é fundamental considerar, além dos totais mensais e anuais das precipitações, analisar, também, o período de frequência com que ocorrem essas precipitações. Em outro aspecto, pode-se afirmar que a água pluvial é de suma importância para a manutenção dos recursos fluviais e como modeladora das paisagens. Coelho Netto, destaca que:

A água constitui um dos elementos físicos mais importantes na composição da paisagem terrestre, interligando fenômenos da atmosfera inferior e da litosfera, e interferindo na vida vegetal animal e humana, a partir da interação com os demais elementos do seu ambiente de drenagem. Dentre as múltiplas funções da água destacamos seu papel como agente modelador do relevo da superfície terrestre, controlando tanto a formação como o comportamento mecânico dos mantos de solos e rochas (COELHO NETTO, 1998, p. 93).

Nesse contexto, verifica-se a importância de pesquisas relacionadas ao volume e a distribuição pluviométrica regional. Entende-se, que a precipitação está inteiramente ligada a temperatura do ar, assim, foi analisado também este elemento do clima. Segundo Conceição, Maia e Lima (2016), a temperatura do ar, assim como a distribuição hídrica, é crucial para manutenção de vidas na terra, sobretudo na disponibilidade do vapor d'água.

Assim, o presente estudo tem o propósito de analisar o índice de precipitação mensal e dias com chuva no município de Ituaçu, tendo como base os anos de 2000 a 2015. A pesquisa é de grande importância para o município de Ituaçu, haja vista que os resultados poderão subsidiar planejamentos das atividades agrícolas e alertas à população sobre os possíveis efeitos das precipitações para o município, tanto em relação aos longos períodos de seca, quanto aos danos provocados pelo excesso de chuva.

De acordo com a Superintendência de Estudos Econômicos e Sociais da Bahia (SEI, 2016), O município de Ituaçu (Figura 01) possui um clima semiárido e subúmido a seco com uma vegetação diversificada entre Caatinga Arbórea aberta, sem palmeiras, contato caatinga-floresta estacional. O município está assentado no Domínio dos Planaltos em Estruturas Dobradas e Região do Plediplano Central. Com relação aos aspectos geológicos o município compreende estruturas antigas denominadas de Formação Seabra, Formação Tombador e Grupo Bambuí, este se encontra no centro do sinclinal de Ituaçu, sul da Chapada Diamantina (BRASIL, 1981). 


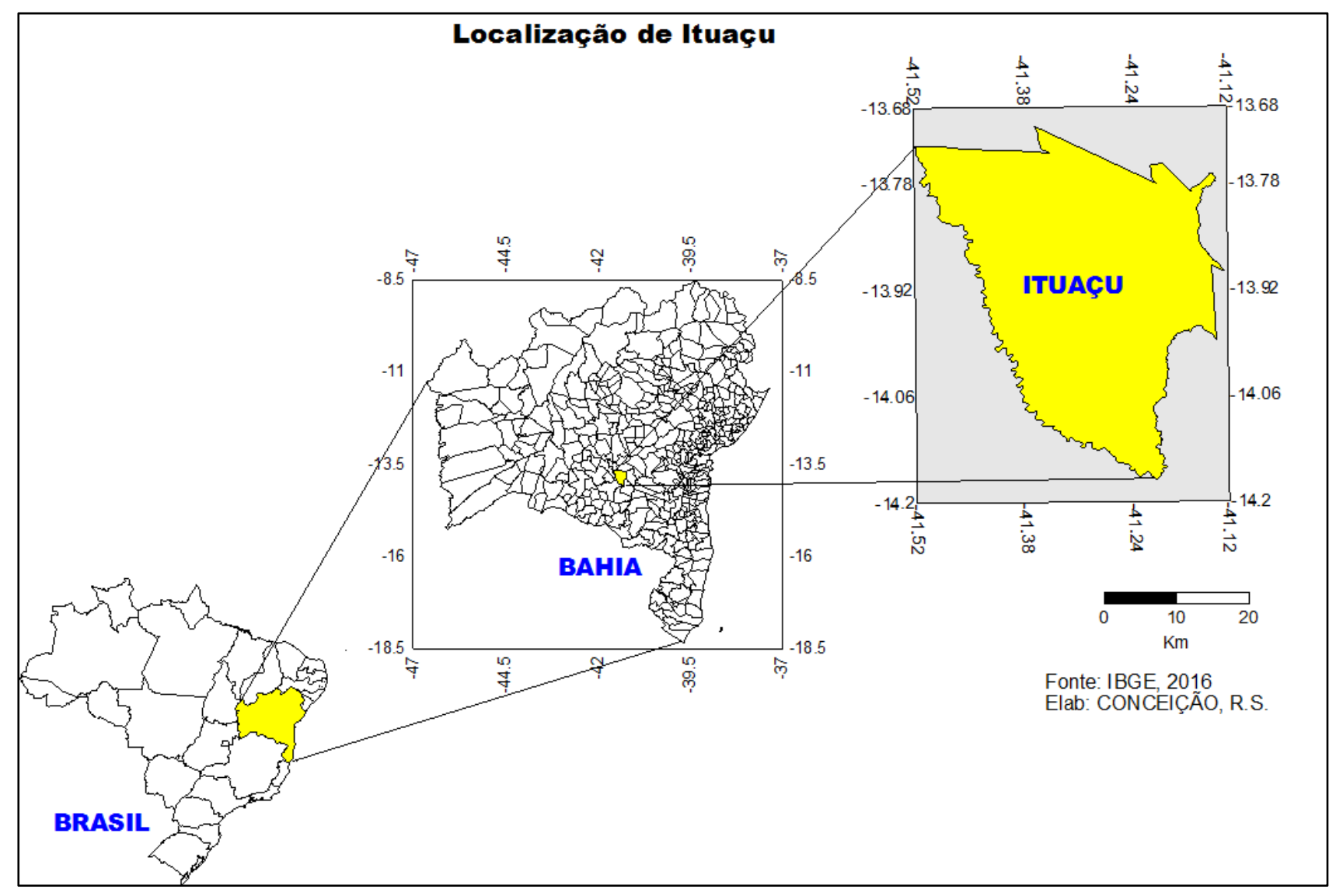

Figura 1. Localização do município de Ituaçu - BA, 2016.

Ituaçu possui uma população de 18.127 habitantes (IBGE, 2010) e está situado na Messoregião Centro Sul Baiano e Microrregião de Brumado, no Semiárido Baiano. A região semiárida brasileira estende-se uma área total de $895,254.00 \mathrm{~km}^{2}$ constituída de 1.031 municípios, abrangendo grande parte de oito estados brasileiros no todo ou em parte (BRASIL, 2004). É uma região que se destaca no cenário brasileiro pelas características naturais heterogêneas mesmo que, de forma geral, apresente temperaturas médias anuais elevadas $\left(27^{\circ}\right.$ a $\left.29^{\circ} \mathrm{C}\right)$, solos rasos, vegetação de caatinga e precipitações irregulares e torrenciais (AB`SABER, 1980).

\section{METODOLOGIA}

Para a realização deste trabalho foi realizada uma revisão bibliográfica para melhor compreensão da temática estudada, assim como pesquisas nos sites do Instituto Brasileiro de Geografia e Estatística (IBGE) e Superintendência de Estudos Sociais e Econômicos da Bahia (SEI) para maior aprofundamento dos aspectos físico-ambientais de Ituaçu. 
Os dados de precipitação diários, dias com chuvas e temperatura do ar de 2000 a 2015 utilizados nessa pesquisa, foram adquiridos no Instituto Nacional de Meteorologia (IMNET), estação de Ituaçu localizada nas coordenadas $13^{\circ} 49^{\prime}$ latitude Sul e $41^{\circ} 18^{\prime}$ longitude oeste. Essas informações estão disponíveis online, pela mesma instituição. Foram analisados, também, dados da normal climatológica (1961-1990) e balanço hídrico do município. O uso do Software Excel possibilitou a geração de gráficos de temperatura média, precipitação mensal e dias com chuvas para os anos de 2000 a 2015.

Para a elaboração do mapa de localização do município em análise, utilizou-se o software MapViewer 7.2 e as bases cartográficas vetoriais no formato shapefille, disponíveis no IBGE. O período curto de análise (2000 a 2015) configura-se numa estratégia de abranger um estudo com resultados mais detalhados para a interpretação da dinâmica pluviométrica local.

\section{RESULTADOS E DISCUSSÃO}

A análise das dinâmicas pluviométricas dos municípios configura-se como uma relevante estratégia de planejamento ambiental, pois estas permitem conhecer melhor as características naturais do município e podem dar suporte as ações de ordenamento e gestão do território. Nesse sentido, considera-se que os dados de temperatura, precipitação e dias com chuvas possibilitam elaborar um panorama acerca das características na escala municipal.

Com relação à análise da temperatura do ar de Ituaçu no período entre 2000 e 2015 verificou-se que o município exibe temperaturas elevadas em todos os meses dos anos estudados, com médias mensais superiores a $22{ }^{\circ} \mathrm{C}$. Foi possível constatar que o município mantém poucas variações nos índices da temperatura ao longo do ano. No verão ocorrem temperaturas entre 27 e 28 ${ }^{\circ} \mathrm{C}$ e no inverno as médias mensais oscilam entre 22 e $25^{\circ} \mathrm{C}$. No entanto, nos meses de novembro e dezembro de 2015, registraram-se as maiores temperaturas dos anos em análise. Esses meses apresentaram no ano de 2015 , médias mensais de 31 e $30^{\circ} \mathrm{C}$, respectivamente.

Com relação às precipitações, as análises permitiram inferir que nos anos estudados, o município apresentou totais anuais com desvio negativo em relação a normal, com exceção dos anos de 2000, 2002, 2006 e 2007 que apresentaram totais anuais acima da normal. A média para os dezesseis anos foi de 562,2 mm, enquanto a normal para do município é de 710,7mm. Ou seja, houve um desvio negativo significativo na média do período em relação a normal.

Os anos 2000, 2002 e 2014 apresentaram desvios positivos, em relação à média, nos meses de dezembro (308 mm), janeiro $(284 \mathrm{~mm})$ e dezembro $(216 \mathrm{~mm})$, respectivamente. As médias para o período é de $84,4 \mathrm{~mm}$ para o mês de janeiro e $84,5 \mathrm{~mm}$ para o mês de dezembro. 
De 2008 a 2015 todos os anos apresentaram precipitação abaixo da normal, isso significa que o município tem sofrido com longos períodos de estiagem há oito anos. Pois, além da diminuição das precipitações a distribuição tem se apresentado bastante irregular em todos os anos analisados.

No que tange a correlação das precipitações anuais, elencou-se os anos de 2006 e 2012, visto que esses se apresentaram atípicos durante o período estudado. $\mathrm{O}$ ano de 2012, caracterizado pelo baixo índice pluviométrico com $292 \mathrm{~mm}$, portanto, com 41,08\% abaixo da média e o ano de 2006, que registrou a pluviosidade anual de $790 \mathrm{~mm}, 11,2 \%$ acima da média. Esse total de precipitação anual, foi o maior de todo período estudado. É importante destacar que durante os dezesseis anos estudados, $75 \%$ deles apresentaram médias anuais abaixo da normal climatológica (Figura 2).

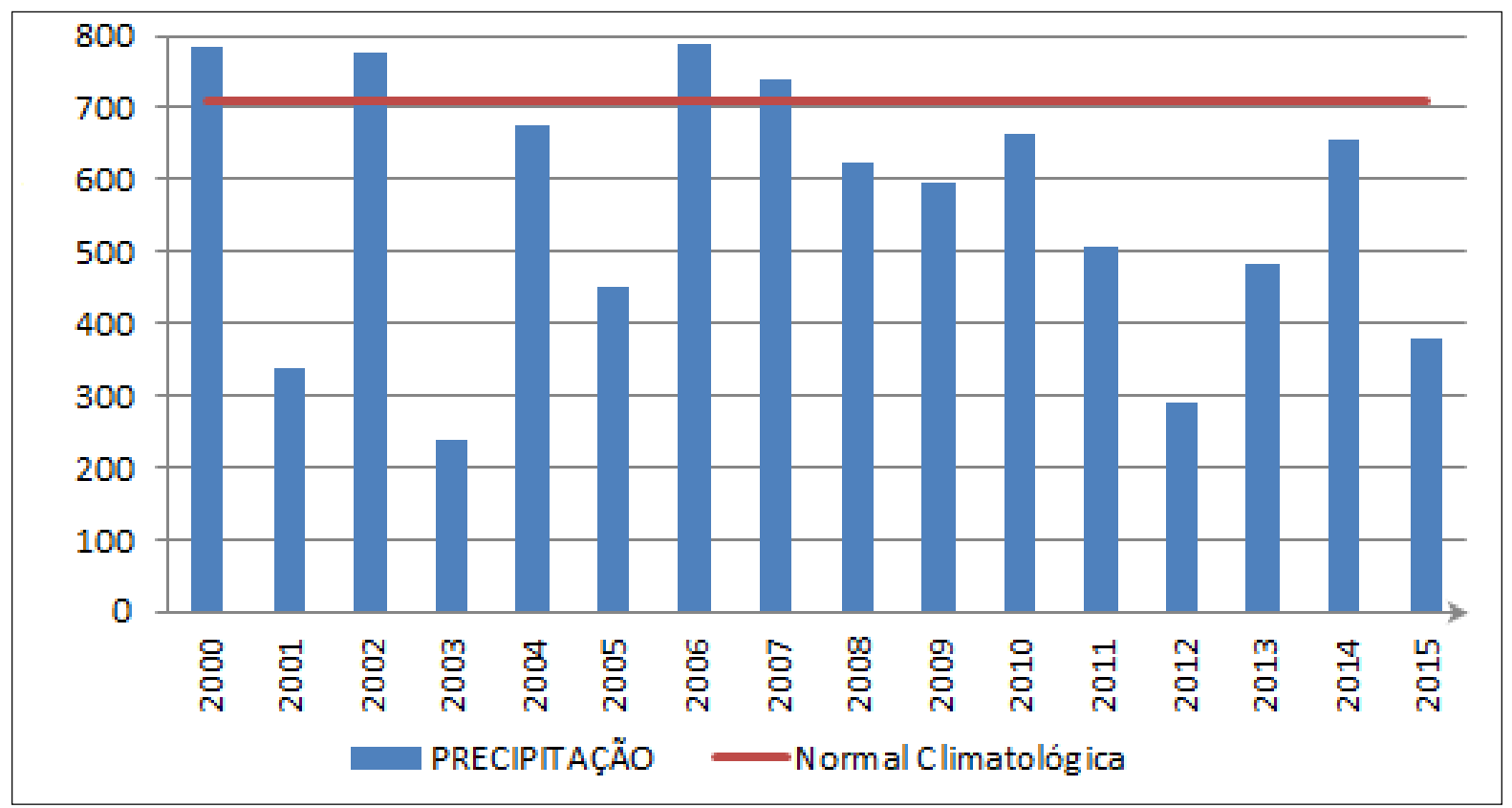

Figura 2. Precipitação total e normal climatológica - Município de Ituaçu, 2000-2015.

Fonte: INMET. Organizado pelos autores, 2016.

No ano de 2012, considerado atípico pelos baixos índices pluviométricos, registrou precipitação $41 \%$ inferior a normal climatológica, foi possível inferir que no mês de dezembro a precipitação foi de $4 \mathrm{~mm}$, ou seja, choveu 95,1\% abaixo da média para o mês.

O ano de 2006 apresentou o mais alto índice pluviométrico durante o período analisado, registrando a média pluviométrica de $790 \mathrm{~mm}$, com desvio positivo de $70,3 \mathrm{~mm}$ em relação a normal climatológica do município. Sublinha-se que o regime pluviométrico, nesse ano, não foi afetado pela anomalia atmosférica El Niño, classificado pelo Centro de Previsão de Tempo e 
Estudos Climáticos (CPTEC) como de fraca intensidade, pois em anos de El Niño forte há uma tendência de diminuição das precipitações na região.

Com relação à distribuição das precipitações, observou-se que o município apresenta uma grande irregularidade (Figura 3), variando entre 120 e 35 dias de precipitações anuais, com uma média de 71,6 dias de chuva por ano. Destaca-se que, as chuvas ocorrem, muitas vezes, de forma bastante concentrada, causando sérios transtornos para a população do município. Um caso bem atípico pode ser observado no mês de outubro de 2009, quando num intervalo de sete dias choveu $185 \mathrm{~mm}$, num mês que apresenta media de precipitação de $23,5 \mathrm{~mm}$. Outro caso que merece destaque é o mês de novembro de 2012, que em dois dias choveu $64,04 \%$ do total anual.

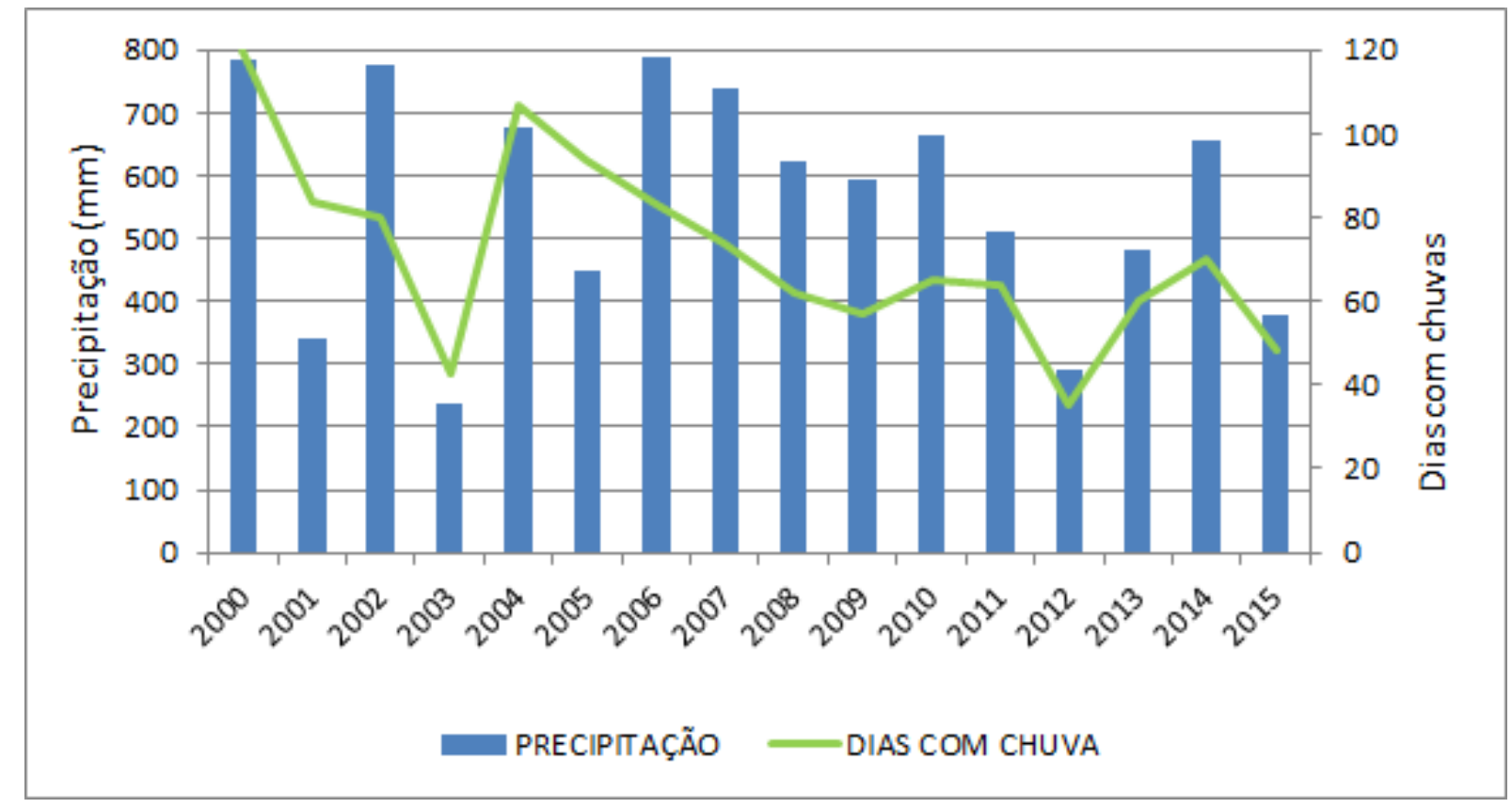

Figura 3. Precipitação total e dias com chuvas - Município de Ituaçu, 2000-2015.

Fonte: INMET. Organizado pelos autores, 2016.

Na Figura 4, observa-se a irregularidade na distribuição da precipitação e dias com chuva para o município de Ituaçu no ano de 2013. O Gráfico demonstra a concentração mensal das precipitações, onde os meses de janeiro e dezembro se destacam com $180 \mathrm{~mm}$ e $150 \mathrm{~mm}$ de precipitação, respectivamente e o mês de fevereiro não apresenta precipitação. Com exceção para os meses de maio (49 mm) e junho (39 mm), os demais meses apresentaram precipitação abaixo de 20 mm. Constata-se, ainda, a existência de poucos dias com chuva. Os meses de fevereiro a novembro de 2013, não apresentam mais que oito dias mensais com chuva. Outro aspecto que chama atenção é que para janeiro desse ano, em 11 dias choveu $180 \mathrm{~mm}$ e dezembro 12 dias com chuva e $150 \mathrm{~mm}$. Assim, pode-se afirmar que em 2013, o município sofreu um período de longa estiagem e dois meses de aguaceiros. 


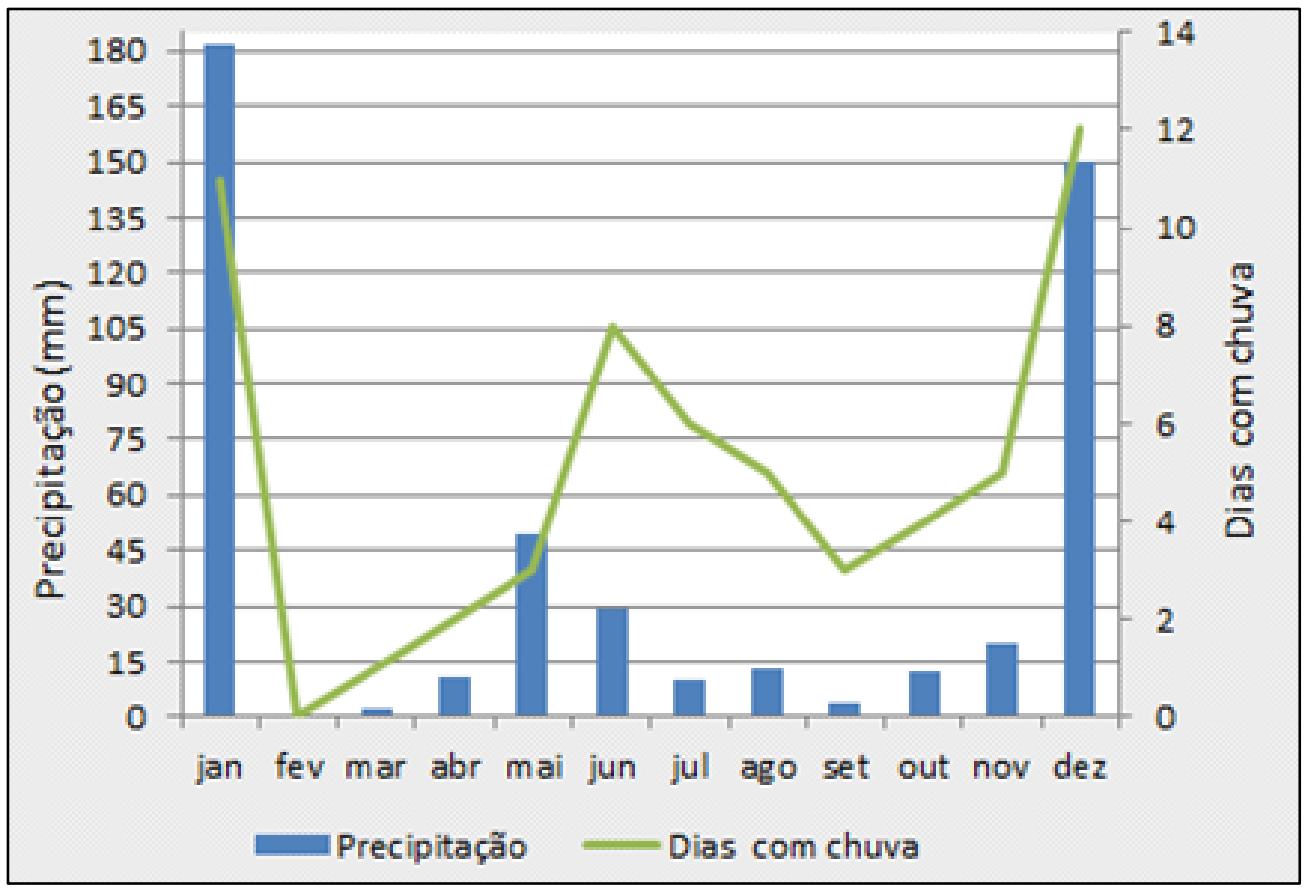

Figura 4. Pluviometria mensal das precipitações e dias com chuva no ano de 2013, Ituaçu - BA. Fonte: INMET. Organizado pelos autores (2016).

Dessa forma, pode-se afirmar que o município de Ituaçu, apresenta alertas para a população em relação aos períodos de longas estiagens e também os de pluviometrias elevadas. Isto é, o município durante o período estudado (2000 a 2015), sofreu com a presença de eventos extremos de escassez e de excessos de chuvas.

Os meses de novembro, dezembro e janeiro foram os meses nos quais ocorreram eventos extremos positivos. Por exemplo, as chuvas que ocorreram no dia seis de novembro de 2012, deixaram a cidade alagada, o que ocasionou prejuízos à população, além de ter danificado a infraestrutura urbana da cidade.

\section{CONSIDERAÇÕES FINAIS}

Diante dos dados analisados e resultados obtidos, é possível afirmar que Ituaçu é um município que apresenta clima semiárido, temperaturas do ar elevadas em todos os meses do ano e baixa amplitude térmica. Em relação ao índice pluviométrico, constata-se que o município apresenta extremos de precipitação positiva e de estiagem com mudanças abruptas e irregularidade em relação às médias de precipitações mensais e anuais. Os resultados obtidos indicam uma complexidade das chuvas no município, tanto em quantidade quanto em distribuição espacial e temporal, ainda que dominem as condições de semiaridez. 
Com os resultados acerca dos poucos dias com chuva em todos os anos estudados, fica visível o alerta de atenção à vulnerabilidade dos recursos hídricos à população. Políticas de subsídio e planejamentos ambientais precisam ser consideradas em todos os meses do ano.

Portanto, sublinha-se o alerta em relação à instabilidade da atmosfera local e vulnerabilidade dos recursos hídricos para o município. Assim, necessita-se de medidas mitigadoras de apoio para Ituaçu, haja vista que esta situação pode acarretar sérios riscos ambientais, assim como implicações para produção agrícola e sérios problemas econômicos e sociais à população. A diminuição na média das precipitações em relação a normal é um fato preocupante, que deve ser considerado pelos administradores nos planejamentos para o município.

\section{Referências}

AB`SÁBER, A. N; 1980: O domínio morfoclimático semi-árido das caatingas brasileiras. Craton \& Intracraton escritos e documentos. São José do Rio Preto, IBILCE-UNESP, nº.

BAZZANO, M. G. P.; ELTZ, F. L. F.; CASSOL, E. A. Erodibilidade, coeficiente de chuva, padrões e período de retorno das chuvas de Quaraí, RS. Revista Brasileira de Ciência do solo. Campinas, SP, v. 31, n5, p. 1205-1217, 2007.

BRASIL.Ministério do Meio Ambiente. Brasília, 2004. Programa de Ação Nacional de Combate à Desertificação e Mitigação dos Efeitos da Seca PAN-Brasil. Disponível: em: <http://www.mma.gov.br/estruturas/sedr_desertif/_arquivos/pan_brasil_portugues.pdf >. Acesso em: 26/07/2016.

BRASIL. Ministério das Minas e Energia. Secretaria Geral. Projeto RADAMBRASIL. Folha SD24 Salvador; geologia, geomorfologia, pedologia, vegetação e uso potencial da terra. Rio de Janeiro, 1981.

COELHO NETTO, A. L. Hidrologia de encosta na interface com a geomorfologia. In: GUERRA, A. J. T.; CUNHA, S. B. da. Geomorfologia: uma atualização de bases e conceitos. 3 ed. Rio de Janeiro: Bertrand Brasil, 1998. 472p.

CONCEIÇÃO, R. S.; BARROS. L. B.; VEIGA. A. J. P. A temperatura do ar e sua Relação com Algumas Doenças Respiratórias em Vitória da Conquista-BA. Revista Eletronica Geoaraguaia. 2015. v.2 Barra do Grarças-MT.

CONCEIÇÃO, R. S.; MAIA, M. R.; LIMA, E. M. Características Climáticas do Município de Jequié-Ba a partir do Balanço Hídrico. In: SEABRA. G. (ORG). Educação Ambiental e Biogeografia. Ituiutaba-MG: Barlavento, 2016.

CONTI, J. B.; FURLAN.; S. A. Geoecologia o clima, os solos e a biota. In: ROSS, J. L. S. (org.). Geografia do Brasil. 6. Ed., 1reimp. São Paulo: Editora da Universidade de São Paulo, 2011. 
IBGE. Instituto Brasileiro de Geografia e Estatística. Cidades. Disponível em: < http://www.cidades.ibge.gov.br/xtras/perfil.php?lang=\&codmun=291720\&search=bahia|ituacu > . Acesso em: 29/06/2016.

MONTEIRO, C.A.F. Fatores climáticos na organização da agricultura nos países tropicais em desenvolvimento - conjecturas sobre o caso brasileiro. In: Climatologia. No 10, São Paulo: IGEOGUSP, 1981.

SANTOS, J. W. M. C. Ritmo Climático e Sustentabilidade sócio-ambiental da agricultura comercial da soja no Sudeste de Mato Grosso. Revista do Departamento de Geografia (USP), v. 1, n. esp., p. 1-20, 2005.

SEI. Superintendência de Estudos Econômicos e Sociais da Bahia. Disponível em: <http://www.sei.ba.gov.br/index.php>. Acesso em: 30/06/ 2016.

SUDO, H. Processos Erosivos e Variabilidade Climática. In: SANT'ANA NETO, J. L; ZAVATTINI, J. A. Variabilidade e mudanças climáticas: implicações ambientais e socioeconômicas. Maringá: Eduem, 2000.

\section{AGRADECIMENTOS}

Agradecemos ao grupo de pesquisa Análise Ambiental, Planejamento e Gestão Territorial (APLAGET), ao Laboratório de Geografia Física (LAGEF) e a Universidade Estadual do Sudoeste da Bahia (UESB), que nos deu apoio para realização da pesquisa.

Recebido em: 14/08/2016

Aceito para publicação em: 01/10/2016 